\title{
ONS SUID-AFRIKAANSE KINDERHELDE
}

Lt A.M. le Roux*

Since Youth Year is celebrated this year it is only suitable that tribute should be paid to the many child heroes that South Africa produced in the past. This article lifts out a few of these young children, describing the particular circumstances of their heroic deeds.

\section{Inleiding}

Met die dat ons vanjaar Jeugjaar vier is dit nie onvanpas om ons geheue weer te verfris en terug te dink aan soveel kinders wat hulle lewens vir volk en vaderland opgeoffer het nie. Vroeër in die Voortrekkertyd is iemand onder sestien jaar as 'n kind beskou. Seuns het sodra hulle 16 jaar oud geword het, in die ou Transvaal dienspligtig geword en in die tyd van die Groot Trek is 'n dogter van 16 jaar as 'n jong meisie beskou. Hulle het 16 as 'n ouderdom beskou waarop 'n kind selfstandig begin dink het.

Moed, durf, deursettingsvermoë en pligsgetrouheid is maatstawwe van heldhaftigheid by ' $n$ kind
- 'n daad of lewenshouding waarin een of meer daarvan op 'n besondere wyse tot uiting na vore kom, word 'n heldedaad genoem. ${ }^{1}$

Vanaf 1835-1838 het die Groot Trek plaasgevind en in hierdie jare het duisende mense, veral uit die oostelike dele van die Kaapkolonie, weggetrek om nuwe woonplekke te gaan soek in gebiede wat vandag as die Vrystaat, Transvaal en Natal bekend staan.

Gedurende hierdie tydperk reeds het die SuidAfrikaanse jeug gewys van watter stoffasie hulle gemaak is. In 1838 het Dirkie Uys sy lewe vir sy vader gegee in 'n geveg teen die Zoeloes by Dingaan se stat. (Sien Militaria 15/1).

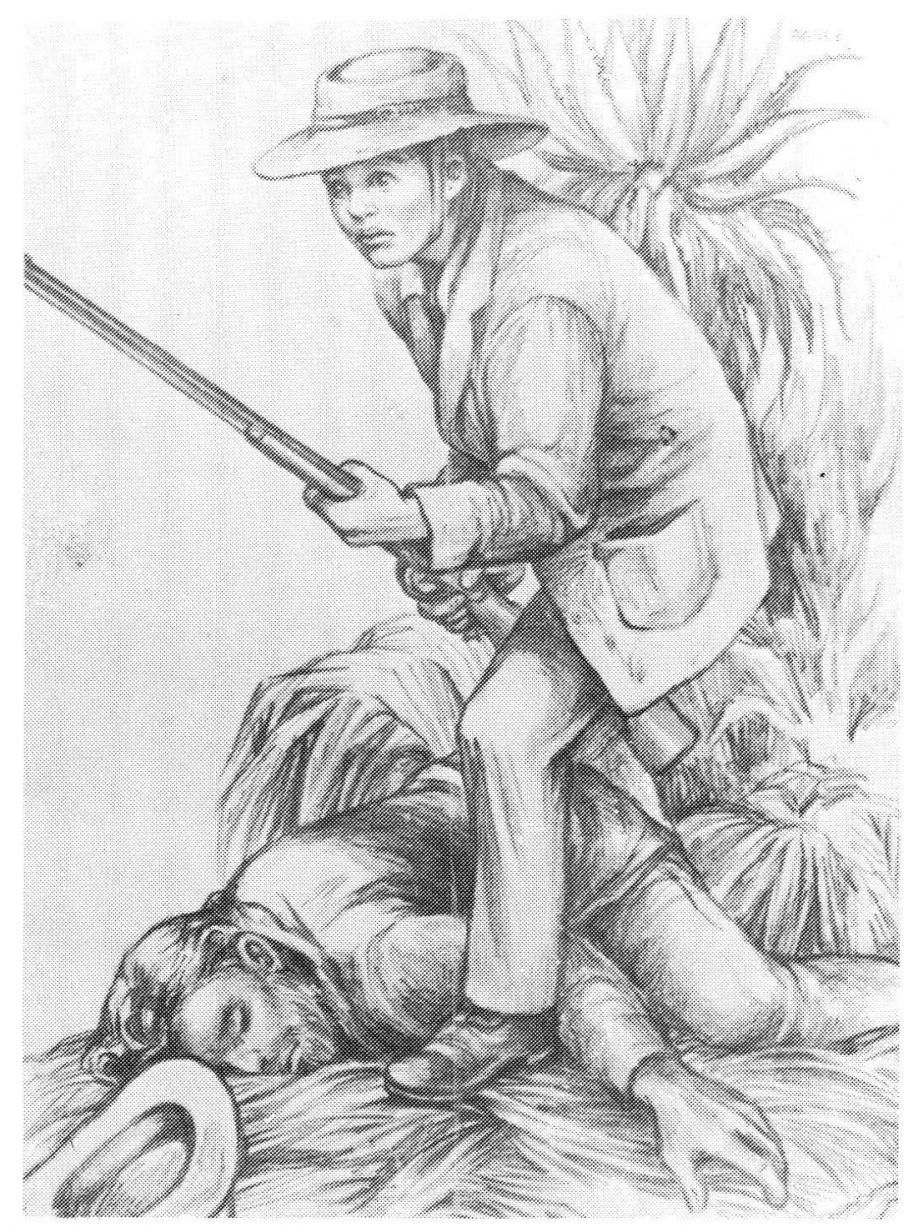

Dirkie Uys het sy vader teen 'n oormag Zoeloes probeer beskerm en met sy lewe vir sy heldedaad geboet 
Marthinus Oosthuizen sal ook onthou word vir sy heldedaad. Met sy perdryvernuf en dapperheid het hy ' $n$ kommando van uitwissing gered. Marthinus was saam met Sarel Cilliers op Trek toe hulle nuus ontvang dat ' $n$ kommando - ongeveer 15 man onder een van die Van Rensburgs - in 'n geveg met honderde Zoeloe-impies, op 'n nabygeleë koppie, betrokke was. Cilliers en sy Trekkers is dadelik soontoe om hulp te gaan verleen en het die Zoeloes van agteraf aangeval. Hulle is egter kort-kort teruggedryf, maar het op 'n stadium so naby aan die mans gekom dat hulle Van Rensburg se boodskap, dat hy 'n tekort aan ammunisie het, kon hoor. Van Rensburg het hulle ook laat weet dat hy wel 'n voorraad besit, maar dat dit verder daarvandaan in 'n wa versteek was.

Marthinus het nie op hom laat wag nie en het deur die Zoeloemassa, in die rigting van die wa gebars. Daar aangekom, het hy soveel moontlik ammunisie gevat en is daarmee terug na die gevegstoneel. Hy moes weer eens deur 'n massa Zoeloes (wat hom gevolg het) bars en het letterlik oor hulle koppe "gevlieg" met sy perd. Van Rensburg en sy manne het die ammunisie dankbaar ontvang en die geveg net nuwe ywer begin. Die Zoeloes is nou van twee kante bestook en die Trekkers wat intussen versterkings bygekry het, kon die geveg wen. Marthinus se daad het meer as vyftien lewens gered.

Flippie Neser en Petrus de Lange was twee Vrystaatse seuns wat in die distrik van Winburg aan die grens tussen die Vrystaat en Basoetoland gewoon het. In 1865 het die oorlog tussen die Vrystaatseburgers en die Basoeto's uitgebreek. President Brand het dadelik die burgers opgekommandeer. Die kommando's het op Winburg byemekaargekom om van daar af die inval teen die Basoeto's te begin.

Volgens landswet kon slegs mans bo 16 jaar opgeroep word om te gaan veg. Flippie en Petrus was albei maar 15 jaar oud en moes derhalwe snags help wagstaan. Die kommando's het Basoetoland binnegetrek tot by Thaba Bosigo - die berg met Mosjes se hootstat bo-op. Die berghange was so steil dat dit onmoontlik was om die stat in te neem.

Vrywilligers is gevra om die berg te bestorm. Die meeste het egter gehuiwer en slegs ' $n$ paar honderd man het op die oproep ag gegee. Onder diegene wat bereid was om hulle lewens te waag was Flippie en Petrus. Toe die twee seuns hulle hulp aanbied het een van die burgers diè smalende opmerking gemaak: "Stuur tog hierdie seuns huis toe om solank die vee op te pas solank die grootmense op kommando is." ${ }^{2}$

Onder leiding van kmdt Louw Wepener het hulle die berg 'n paar dae later bestorm in 'n poging om Mosjes te verslaan. Hulle het moeilik gevorder want die berg was steil en die Basoeto's het hulle van bo-af met klippe en geweervuur gestook. Van die boere het begin moed opgee, maar Flippie en Petrus was onder diegene wat vir Louw Wepener bly volg het.

Die burgers het eindelik die eerste skans ingeneem en na die tweede een begin storm. Hulle was egter nie lank daar nie en moes toe plek maak vir die ander burgers wat intussen aangekom het. Tussen die tweede en die derde skans is Wepener swaar gewond en is hy kort daarna oorlede. Die dood van hulle kommandant, swak lig, die steeds vegtende Basoeto's en die feit dat net ' $n$ handjievol burgers die bopunt bereik het, het die burgers onder wie Flippie en Petrus, laat besluit om om te draai. Die oorlog is vir eers daar gestaak, maar dit was nie die einde van die oorlog teen die Basoeto's nie. Rooftogte het gereeld voorgekom en in die begin van 1866 het die Vrystaatse Regering weer teen die Basoeto's te staan gekom.

In Februarie van daardie jaar is ' $n$ kommando uitgestuur om die Basoeto's in die Maloetieberge te gaan opspoor. Flippie Neser en Petrus de Lange het saamgegaan. Die Basoeto's het 'n klompie beeste as lokmiddel bo-op die berg gejaag. Hulle het gereken dat die boere die beeste sou gewaar en boontoe sou gaan om dit te gaan haal. Die plan het geslaag en terwyl die boere besig was om die beeste af te jaag het die Basoeto's hulle in 'n nou kloof omsingel. In die chaos wat gevolg het, het die twee seuns van die ander losgeraak. Hulle is daar vol koeëlwonde en assegaaisteke oorlede nadat hulle 'n tydlank weerstand gebied en ongeveer ' $n$ dosyn Basoeto's doodgeskiet het.

Ernst von Linsingen was die seun van Wilhelm von Linsingen wat in 1856 saam met die Duitse Legioen na Suid-Afrika gekom het. In 1880 het verwikkelinge in Kafferland plaasgevind wat vir Von Linsingen op die toneel geplaas het. In OKtober van daardie jaar het die Temboe- en Galekastamme oorkant die Basjeerivier in opstand gekom. Hulle wou die Kolonie binneval en het gehoop dat die Fingo's by hulle sou aansluit. 'n Groot aantal Fingo's het besef dat dit dwaas sou 
wees omdat hulle hulle grondgebied kon verloor en het besluit om die Kolonie te help. Die regering het besef dat dit 'n uitgerekte oorlog kon afgee en het Von Linsingen genader om na die oosgrens te gaan en die leiding van die veldtog op sy skouers te neem.

Baron von Linsingen was toe reeds 60 jaar oud en sy seun Ernst (16 jaar) het saamgegaan. Hulle het vertrek en het op 12 November by die kamp, wat tussen twee bergkoppe geleë was, aangekom. Die troepemag het uit 'n aantal blanke soldate en ongeveer 250 Fingo's bestaan. Op Sondag 14 November, het Von Linsingen sy mense bymekaar geroep om 'n erediens te hou. Kort daarna het die wagte gerapporteer dat hulle vermoed dat die vyand in die kloof naby die kamp was.

Von Linsingen, Ernst en vier soldate het gaan ondersoek instel. Met dié het Von Linsingen die duisende Temboes gewaar, maar hulle was reeds in die hinderlaag. Die ses mans wou uitjaag en het byna daarin geslaag, maar een van die soldate se perde het gestruikel en sy ruiter afgegooi. Met die val het Baron von Linsingen sy been in die heup gebreek. Ernst wat reeds veilig uit was, het teruggejaag, maar kon sy vader nie op die perd se rug kry nie. Hy was stoksielalleen teen die oormag en het aan sy vader se sy aan 'n assegaaiwond beswyk.

Helena Lotrie was die dogter van die beroemde jagter en reisiger Francois Bernard Lotrie. Lotrie het saam met Piet Grobler kameelperde gejag toe hulle deur 'n klomp Bamangwato's besoek is. Hulle het vir Grobler voorgekeer omdat hy in Bamangwato gebied was en nie die hoofman se toestemming gehad het nie. Grobler moes agtergekom het dat dit bloot moeilikheidsoek was omdat die Bamangwato's jaloers was op Grobler se vriendskap met hulle vyand, Lobengoela. Hulle sou later ooreengekom het dat die Bamangwato's slagbeeste sou betaal as vergoeding vir die oponthoud. Grobler het op versoek van die leier 'n dokument laat opstel waarin die vergoeding beskryf is.

Die leier het daarop aangedring dat die stuk wat in Engels was aan sy mense getolk moes word. Vir dié doel moes al sy mense en die Blankes bymekaar kom. Hy het ook vereis dat die Blankes ongewapen moes wees, aangesien sy mense ook nie wapens sou saamneem nie. By

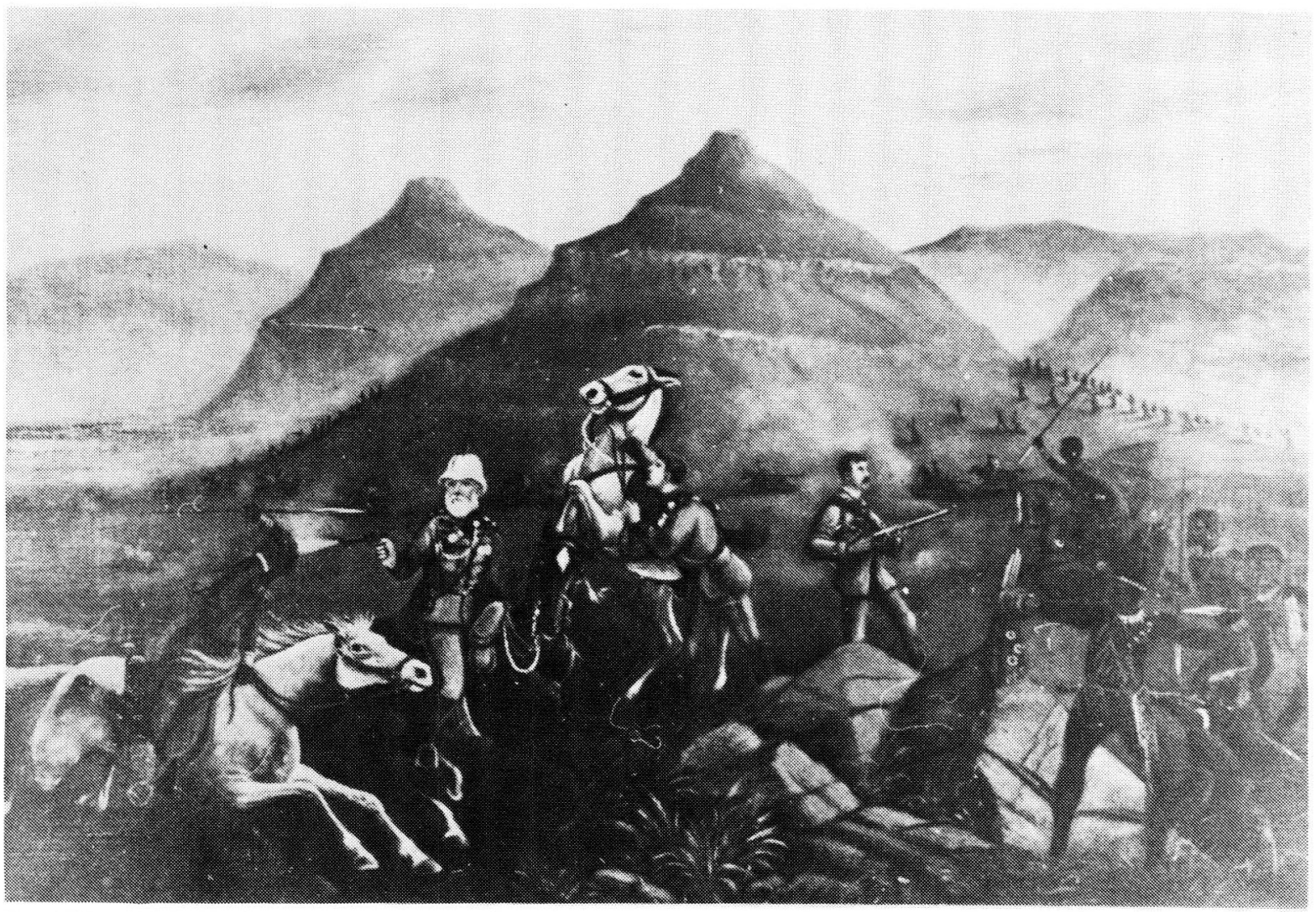

Die skilder, C.C.H. Henkel, se weergawe van die gebeurtenis waartydens Baron von Linsingen en sy seun Ernst vermoor is 
die afgesproke plek het die Bamangwato's in ' $n$ halfmaan gaan sit en sommiges het probeer om tussen die Trekkers en die waens te kom. Grobler het dit egter gou agtergekom, hulle teruggestuur en toe met die tolkwerk begin.

Daarna het die leier opgestaan en geskree: "Julle almal het dit gehoor! Staan op! Gryp hulle en maak hulle dood!"3

Ongeveer 160 Bamangwato's het met assegaaie en knopkieries op die 60 Trekkers toegeslaan. Grobler is in die been gewond en kon nie wegkom nie. Die ander mans kon hom ook nie gaan help nie, aangesien hulle hulle hande vol gehad het met die krygers wat op hulle toegesak het. Om sake nog erger te maak, het die Bamangwato's veral op Grobler geskiet. Dit is daar waar Helena Lotrie die chaos aanskou het en besluit het om hom te gaan help al sou dit haar lewe kos.

Sy het tot by Grobler gehardloop en tussen hom en die Bamangwato's gaan staan met haar rok uitgesprei sodat hulle hom nie kon sien nie. Behalwe vir die paar koeëlgate in haar rok het sy niks oorgekom nie.

In Oktober 1899 het die Tweede Vryheidsoorlog uitgebreek. Alle weerbare manne oor die ouder-

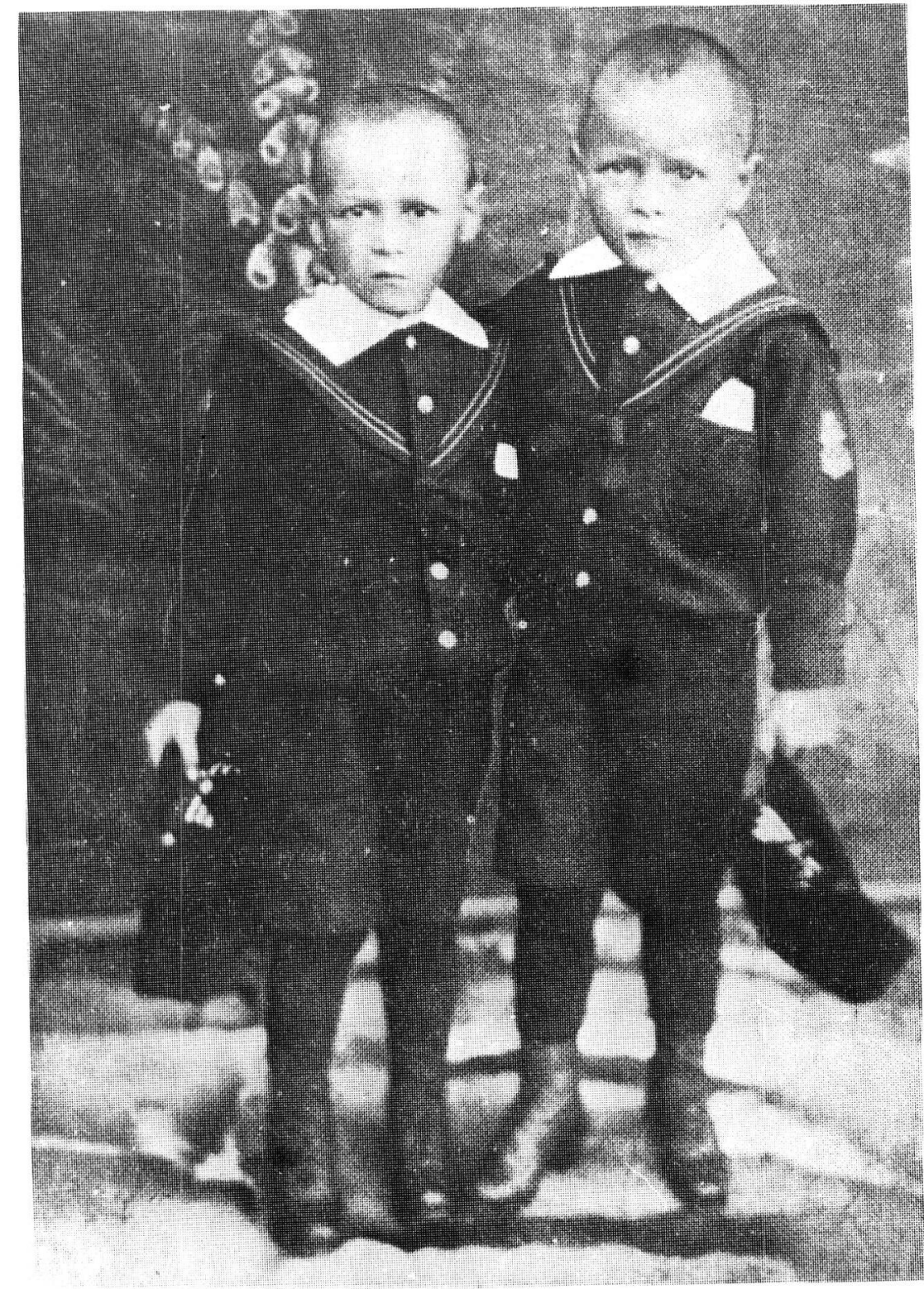

Japie Greyling (regs) het vir hom onsterflike roem as kinderheld verwerf deur te weier om aan die Engelse te sê waar die boerekommando's was. Links staan sy broer Kerneels 
dom van 16 jaar is opgeroep. Jonger seuns kon op eie risiko aansluit. Jan van Kaller was maar 14 jaar oud toe hy by die kommando aangesluit het. Nadat sy vriend in 'n geveg gewond is, het hy man-alleen ' $n$ klomp Engelse soldate met geweervuur in 'n huis vasgekeer - dit was om te voorkom dat hulle op die boere se laer gaan spioeneer. Jan is dan ook later gevang en na 'n krygsgevangekamp in Indië gestuur waar hy later dood is. Japie Greyling sal ook onthou word vir sy dapperheid tydens die Tweede Vryheidsoorlog. Dit was in April 1901 toe Japie op sy vader se plaas, Smaldeel in die Vrystaat teen die Britse kaptein James Seeley te staan gekom het. Op daardie dag het Japie vir hom onsterflike roem as kinderheld verwerf. Japie was skaars elf jaar oud to sy pa saam met die Vrystaatse magte op kommando is.

Daardie nag het ' $n$ paar burgers op Smaldeel oornag, maar moes vroeg die oggend padgee toe 'n afdeling Engelse soldate gewaar is. Nie lank daarna nie het die Engelse op die plaas aangekom. Kaptein Seeley wou dmv ' $n$ tolk van Japie weet waar die Boerekommando was. Japie het egter geweier om enige-iets te sê, nie eers toe hy teen die muur voor ' $n$ vuurpeleton geplaas is nie.

Hierdie was enkele sketse van dade deur kinders in die vroeë geskiedenis. Ons onthou egter ook die dade van Rachel de Beer wat haar lewe opgeoffer het vir haar broertjie en Klara Majola wat haar vader gaan soek het en in die proses verdwaal en verkluim het.

"... dat die dryfkrag van die held die liefde is (vir volk, land medemens of miskien ook vir die self). Die woeste, wrede dade wat uit haat gepleeg word; hoe roekeloos ook, ons gril en huiwer sonder om ons in die hart te gryp. Ja, die heldedom kom uit die liefde voort, en nie uit haat nie". ${ }^{4}$

*Lt A.M. le Roux, Honns Joernalistiek en Sakakelkunde is verbonde aan die Militêre Informasieburo van die SAW.

\section{Verwysings}

1. Kotze, D.J. (Dr) Dapper Kinders van Suid-Afrika, Die Sondagskool-Boekhandel, Bloemfontein, 1978. p 11.

2. Ibid, $p 74$.

3. Ibid, $p 97$.

4. Grobbelaar, P.W. Die Groot Afrikaanse Heldeboek, Human en Rousseau, Kaapstad, p 224. 